Lepr Rev (1989) 60, 1-7

\title{
Editorial
}

\section{PRIORITIES IN LEPROSY CONTROL}

In the recently published Sixth Report of the World Health Organization Expert Committee of Leprosy (1988), the world prevalence is estimated to be between 10 and 12 million cases. ${ }^{1}$ About one third have significant deformities. More than 1.6 billion people live in countries where the estimated prevalence is above 1 per 1000 of the population and who are therefore at risk of infection. But in recent years, leprosy has been recognized as a ma jor health problem in many endemic countries and the recommendations of the World Health Organization (WHO) in 1982 on regimens of multiple drug therapy (MDT) of relatively short duration ${ }^{2}$ opened new and unprecedented perspectives for leprosy control. Today leprosy can be seen not as 'an historic fatality but as a problem with a solution'. ${ }^{3}$ The implementation of MDT as standard treatment has become a prime strategic priority for leprosy control programmes. The objectives of leprosy control have been clearly stated, the methods well defined and the most important 'essential' or 'key' activities needed for an effective leprosy control programme described in considerable detail. ${ }^{4-6}$ In the context of the global policy of 'health for all' it is now generally accepted that leprosy control should be implemented into general health services, using the primary health care approach. The problem, as usual with the control of any major disease, is bridging the gap between words and action.

At the recent 13th International Leprosy Congress in The Hague, many words were spoken on virtually all aspects of leprosy but with notably few contributions on operational aspects, as opposed to laboratory-based research. Opinion is still divided not only on the total list of priorities in leprosy but also on their relative importance or ranking. Experts are bound to differ. Immunologists may emphasize the importance of the development of a vaccine and serological tests for susceptibility, subclinical infection, clinical disease and leprosy reactions-and few would question the need for continued support of such research. Clinicians may highlight diagnosis, classification, chemotherapy and management. Epidemiologists may call for the collection and detailed analysis of more data on incidence, prevalence, disability and relapse rates, while sociologists will underline the importance of remembering that there is much more to leprosy than a mere bacterial infection. Pharmacologists, whilst acknowledging the efficacy of the drugs actually available, may (with considerable justification) call for research on new compounds, and finally, microbiologists may return to the long-standing problem of achieving in vitro growth of the bacillus. Many of these claims are valid, but the resources are limited and a choice often has to be made between what needs to be resolved now and what could be developed, perhaps with great benefit, for use in the future.

The priorities are not easy to define and are even more difficult to place in order of importance. For the purpose of this paper we propose to discuss the subject under two headings- 'Strategic' and 'Operational'-but recognizing that in reality they are interwoven. 


\section{Strategic priorities}

\section{IMPLEMENTATION OF MDT}

The Third Coordinating Meeting on Implementation of Multidrug Therapy in Leprosy Control, held recently in The Hague, recorded significant progress in leprosy control activities and the coverage of leprosy patients with MDT. Over the past few years some leprosy endemic countries have increased their budget for MDT leprosy control and substantial contributions have been made by members of the International Federation of Antileprosy Associations (ILEP) and the Japan Shipbuilding Industry Foundation (JSIF).

The number of registered cases in 1985 was 5.4 millions, a figure which represents an increase of $90 \%$ over that of $1966 .{ }^{1}$ In 1987 the registered total was $5 \cdot 1$ millions, a reduction which has been related $^{7}$ to the drug treatment and release of large numbers of patients, thus supporting the efficiency of multiple drug therapy as recommended by WHO in 1982. From these figures, it can be seen that only about half of the estimated total are registered. About one third are receiving regular treatment. Although progress is indeed being made in the implementation of MDT, with recent indications of an upward trend in the graph, the fact is that a full 6 years af ter the publication of the WHO recommendations, the total number of patients who have so far received MDT is only just over 2 million (of whom over a quarter have completed treatment and are no longer considered to have the disease). Despite the efforts which are being made, of ten in the face of considerable odds, it is thus probable ${ }^{3}$ that between 8 and 10 million patients with leprosy are not benefiting from a form of treatment which is available and manifestly effective. It is particularly worrying that in Africa with 600,000 registered patients only about 50,000 (8.2\%) are on MDT. Nigeria, which harbours more than 160,000 registered patients has only $3 \cdot 2 \%$ on MDT and other countries (Zaire and Uganda) have not yet introduced it.?

It is obvious that a priority of the utmost importance globally is the more rapid expansion of MDT, and that the achievement of such a task depends on the understanding and full commitment of national governments, non-governmental organizations and international contributing agencies, as well as effective coordination between them for the utilization of resources.

\section{ACCEPTANCE OF WHO-RECOMMENDED MDT REGIMENS}

Another important aspect of MDT centres on the global acceptance and implementation of WHOrecommended regimens for multibacillary (MB) and paucibacillary (PB) leprosy. In the late 1970s, mainly because of the increasing problems of dapsone resistance, various regimes of multiple drug therapy were proposed and applied quite widely. The Fifth Report of the WHO Expert Committee on Leprosy in $1977^{8}$ strongly recommended further investigation into multiple drug regimens. However, in the following years, and even after the publication by WHO in 1982 of recommendations for the treatment of all cases with MDT, other regimens, or significant modifications of the WHO regimens, have been used. Whilst some of these appear to have been successful, none, to our knowledge, has been shown to be superior in terms of clinical and bacteriological cure, acceptability by patients and staff, toxicity, or relapse rates to those so clearly recommended by WHO in 1982 . The use of multiple drug regimens other than those recommended by WHO significantly complicates the whole process of the training of staff, education of patients, drug ordering and dispensing. Unless definite advantages for non-WHO regimens can be established, there is surely a case for encouraging government and non-government agencies to use the WHO regimens whenever possible.

\section{INTEGRATION}

The policy of implementing MDT leprosy control as an integral part of the primary health care 
system has received increasing acceptance in recent years. The rationale for this concept, elegantly reviewed by Feenstra and Tadele Tedla, ${ }^{9}$ is that comprehensive and continuous leprosy services, with the widest possible availability, can be best delivered through a decentralized health care system. The strategy and method of procedure for integration have however not yet been well defined. Where leprosy endemicity is high and the development of health services inadequate to meet the demands of MDT control, a specialized national programme would be the rational approach. However the strategy of such programmes should, from the outset, be to progressively change from vertical to horizontal, i.e. from specialized to general health care, involving primary health care staff in leprosy control activities and preparing the general services to take full responsibility in future. On the other hand, integrated leprosy control services cannot function efficiently without the element of specialized technical support. There are striking examples of specialized, national leprosy control programmes (India), as well as integrated programmes (Indonesia).

Regrettably, there are already indications that in either of these situations the system is not working satisfactorily. One of us (GDG) recently visited seven countries in west and south-east Africa as part of a feasibility study on the teaching of leprosy ${ }^{10}$ and this included discussion with people in ministries of health, leprosy control programmes and other relevant organizations. One of the disconcerting findings was that some programmes, although officially integrated and under ministry of health direction, in fact retain to a great extent the attitudes of 'vertical' control projects. This has the effect of isolating leprosy programmes from health care development in general and in many areas, the participation of medical and health staff at district level has been minimal and their training in leprosy non-existent. In some programmes, the coverage of patients for MDT, even after 6 years, was only $10-30 \%$, case detection rates remained low and disability rates unacceptably high. The lesson to be learned is that the entire process of integrating leprosy control into general health services, whether $a b$ initio, or from a previous specialized service, has to be planned in detail, including the creation of positive attitudes for close cooperation between non-government organizations and ministries of health.

\section{TRAINING OF MEDICAL AND HEALTH STAFF}

The importance of relevant, adequate and proper training of all medical and health staff in leprosy has been repeatedly stressed in a number of WHO and ILEP documents and re-emphasized during the 13th International Leprosy Congress. The methodology of task-orientated teaching of leprosy has been excellently described and abundant teaching and learning materials and aids, including slides, films and video recordings have been developed in recent years. ${ }^{11}$ However, it is common knowledge that very little has been done to improve leprosy teaching in medical and paramedical schools. During the study for the promotion of leprosy teaching referred to above, ${ }^{10}$ with a few notable exceptions, the findings were more disconcerting than might have been predicted. It has for many years been generally known (and for the most part not denied by schools in various parts of the world) that the teaching of medical and paramedical students about leprosy, and particularly leprosy control, is inadequate, and this was amply confirmed in the above study. In brief, it was found that there is an urgent need for the introduction of basic leprosy teaching into the curricula, as well as in continuing and distance education systems, not only for medical students (who have often been singled out), but for virtually all cadres of the health staff. A systematic approach and sustained efforts for relevant and adequate training in leprosy cannot be over emphasized, if integrated leprosy control, depending on the safe and effective implementation of MDT is to succeed. This experience f rom a continent in which only $8 \cdot 2 \%$ of all registered cases have so far been treated with $\mathrm{MDT}^{7}$ points to the subject of information distribution, teaching and training as one of the highest priority.

If this conclusion is correct and it is agreed that it calls for action, we may be facing a problem of considerable size and complexity, the implications of which have not yet been fully appreciated. The 
educational and training effort has to be directed at literally hundreds of thousands of the health staff, including teachers. Has the master plan of action been outlined? Should it be pursued by WHO, ILEP, the World Federation for Medical Education, ${ }^{12}$ the International Foundation for Dermatology $y^{13}$ or perhaps in a special programme, supported by all of these agencies? Do the teaching modules exist? Are they available in English, French, Spanish and Portuguese? Where are the courses for training the teachers? Are tuberculosis and common tropical skin conditions to be taught at the same time? Is the money available? Despite the size of this challenge and its complexity and cost, it appears however, to be an almost over-riding priority which, if properly planned and executed, could be a valuable pattern for the teaching of the control of malaria, venereal disease, AIDS, tuberculosis and other major diseases. We hazard the opinion that any progress which can be made in leprosy control in the next 5-10 years will depend mainly on the extent to which the teaching and training of general health service staff in leprosy is turned from words into action. Is there in fact a viable alternative?

\section{Operational research}

The potential benefits of current scientific research, notably on possible vaccines and serological tests, have yet to be declared in terms which are of practical use in control programmes. It is difficult to avoid the comment that the amount of time, money and effort allocated, on an apparently increasing scale, to laboratory-based research in leprosy is perhaps somewhat out of control. At the recent 13th International Leprosy Congress in The Hague, an examination of the published Abstracts ${ }^{14}$ shows that most of the contributions were on immunology, molecular biology or closely related topics; extremely few dealt directly with the operational aspects of leprosy and fewer still were of high quality. If this reflects the availability of funds and a positive selection of subjects for research, then surely the priorities should be revised to acknowledge the pressing needs of operational research in leprosy control and MDT implementation.

It has already been proven beyond any doubt that MDT is an effective tool for leprosy control. What is still not well known and remains controversial, is how best and most efficiently thistool can be used in the national leprosy control programmes. This will include all operational aspects of effective early case finding, prevention of disability, motivation of health workers, patient treatment compliance, family support, community awareness and participation and many others. The evaluation of present operational strategy and methods, and the testing of new technology are other important fields for research.

Relevant operational field-based research requires multidisciplinary involvement of epidemiologists, health economists, social anthropologist and those involved in management on a wide basis. This includes not only those working in specialized leprosy projects but the resources and potential of the universities and research institutions in endemic countries. ${ }^{10}$ Encouragement of operational research and active recruitment of suitable professionals of various specialities and their adequate remuneration, together with at least medium-term career prospects, is essential. In this context, an important invitation has recently been published from the Office of the Special Programme for Research and Training in Tropical Diseases (TDR $)^{15}$ calling for applications from scientists with a capability in field research in leprosy. The main objective is to promote leprosyrelated field research and the list of topics offered for consideration includes 'Operational studies aimed at measuring and improving the effectiveness of leprosy control programmes'.

OPERATIONAL PRIORITIES

\section{Management}

Although the importance of management in health care at both middle and other levels, has been 
recognized in a number of publications, the messages have for the most part still to be translated into action. The word 'management' covers a lot (possibly too much), but if it is understood to include day-to-day administration and decison making; the teaching and supervision of junior staff; the ordering, receipt, storage, dispensing and use of drugs, or equipment; the collection of basic data and maintenance of records; monitoring, assessment and evaluation of health care activities, then it is almost impossible to overstate its importance. The finest plan of action for leprosy control and all the drugs in the world will be useless if the syringes do not fit the needles, inner tubes for the bicycles are 'unobtainable' and the junior staff are poorly taught, badly supervised and underpaid at irregular intervals. Within management and administration, the matter of logistic support in leprosy control calls for study equal in terms of financial backing and professional ability to that which is given to, for instance, immunology. Although it is easier to say this than to devise teaching or learning activities which will bring about the necessary changes in attitude and performance, it is our belief that significant improvement could be brought about by (a) analysing the day-to-day problems on the spot, at the scene of work (rather than in a 'training centre'), and (b) enlisting the cooperation of locally based, indigenous workers in the development of procedures or 'devices' which solve at least some of the problems. For example, has any good studyever been carried out to determine the minimum number of forms and monthly reports needed for good health care management at peripheral level?

\section{Training of health staff at district level}

This subject has already been referred to above in the context of strategic priorities, with emphasis on the need to improve training in leprosy for virtually all categories of health staff. For operational purposes there is new evidence to suggest that the main thrust should be at district hospital level, using continuing education and modules which are based on the real health needs in leprosy and other subjects, including primary health care. ${ }^{10,16,17}$ As already stated, a wide range of health teaching-learning materials on leprosy, for both teachers and students are already available ${ }^{11}$ but this should be backed up, and eventually perhaps replaced by the production of similar material locally, using indigenous (not expatriate) expertise. It is also essential to ensure that staff see that their education is backed by constant logistic support, as described above, for the work they are expected to perform.

\section{New strategies and technology}

It is doubtful if the proposals above can be realized in the foreseeable future without the development of new, dynamic and flexible strategies. ${ }^{18}$ Some of the old ones (for example, the relentless survey of vast numbers of people in populations where it is known that the prevalence is not more than $0 \cdot 1 \%$ ), are completely inappropriate if the main objective is the faster and wider implementation of MDT. Prominent amongst the outstanding needs is a way (or perhaps several ways) of making a rapid assessment of the leprosy situation in any given region or country and the recent WHO paper on this subject ${ }^{19}$ is thus extremely welcome. In the opening paragraphs, Dr S K Noordeen, WHO Chief Medical Officer, Leprosy, draws attention to the difficulties of arriving at a figure for the estimated total of cases in the world and also to the fact that the current, cumbersome methodology, using expensive and difficult sample surveys, may have actually impeded the implementation of MDT, notably in Africa. Elsewhere in this important document, attention is drawn to the value of a systematic clinical and bacteriological examination of all registered cases at the outset of any MDT programme. In some parts of Af rica, it was found ' . . that only one third of them required treatment with MDT: this results in a dramatic drop in the leprosy prevalence rate when the numerator is made of all cases eligible for treatment'.

As still in tuberculosis, ${ }^{20}$ case-finding in leprosy remains a somewhat neglected subject; the methodology for achieving the diagnosis of a larger number of cases, either by self-presentation or 
case-finding has not yet been adequately defined. Apart from the likelihood that integrated programmes, using the entire general health service, will result in the detection of larger numbers of cases, ${ }^{9}$ the use of cured patients, as 'publicity agents' in the community calls for investigation. The potential role of the family in compliance to domicilary treatment, prevention of disability and the social and economic rehabilitation of patients calls for research. ${ }^{21}$ New strategies are also needed to ensure that all patients have a constant supply of all the drugs needed, in adult and child doses, throughout their period of treatment. The use of blister calendar packsf or this purpose has recently been described in some detail. ${ }^{22-24}$ Despite the formidable range of teaching-learning materials which has been available for various grades of health staff working in leprosy for many years, suitably written and illustrated material for patients and their families still needs development. Patients are not fools; many of them are keenly interested in taking medication properly and being cured of their disease; literacy rates in many countries are surprisingly high. Using local expertise we should produce, pre-test, modify and finalize such material not only for treatment, but also for early case detection. ${ }^{25}$

\section{Conclusion}

This paper deals with one aspect of a complex disease, namely its control, with emphasis on field work and operational aspects. We have attempted to address the matter of priorities under the headings 'strategic' and 'operational', giving considerable emphasis to case detection and multiple drug therapy. But success will only be achieved if attention is given, persistently, to a package of activities aimed at control. Writing of tuberculosis, Fox recently commented: 'Short-course chemotherapy is not a panacea, although it offers major benefits for the service, the supervisory staff, the patients and the community. To make an impact many other deficiencies must be tackled successfully.... The challenge is largely to eliminate them all, leaving only the inevitable minor lapses, and to be able to detect and so rectify, even these. ${ }^{20}$

We put the question before, ${ }^{18}$ and repeat it here; why is it that so much money and effort is put into laboratory-based research, and so little into the study of the operational aspects of this disease, for which treatment is available and effective? Should we try harder to define and agree the priorities so that available manpower, money and effort are used to the greatest possible advantage?

87 Lower Radley

A C McDougall

Near Abingdon

Oxfordshire OX14 $3 B A$

England

275 Turnpike Drive

Luton

Bedfordshire LU3 $3 R D$

England

\section{References}

1 WHO Expert Committee on Leprosy. Sixth Report. Technical Report Series 768. WHO: Geneva, 1988.

2 WHO Study Group. Chemotherapy of leprosy for control programmes. Technical Report Series No. 675. WHO: Geneva, 1982.

${ }^{3}$ WHO. Multidrug therapy for leprosy; an end in sight. Brochure presented at the 13th International Leprosy Congress, The Hague, September 1988.

${ }^{4}$ WHO. Report of a meeting on action plans for leprosy Control. New Delhi, 23-25 August, 1982. WHO/LEP/ 83.1.

${ }_{5}^{5}$ WHO Study Group. Epidemiology of leprosy in relation to control. Technical Report Series No. 716. WHO: Geneva, 1985. 
6 WHO. A Guide to Leprosy Control. Second Edition. WHO: Geneva, 1988.

${ }^{7}$ Lopez Bravo L. Global Review of Implementation of MDT. Paper presented at the Third Coordinating Meeting on Implementation of Multidrug Therapy in Leprosy Control. The Hague, 13th September, 1988 (Unpublished).

8 WHO Expert Committee on Leprosy. Fifth Report. Technical Report Series No. 607. WHO: Geneva, 1977.

9 Feenstra P, Tadele Tedla. A broader scope for leprosy control. Wld Hlth Forum, 1988; 9: 53-8.

${ }^{10}$ Georgiev GD, Report on a feasibility study for a proposed project on the teaching of leprosy in medical schools in Africa ('LEPT AMS'). Internal (unpublished) report to LEPRA (British Leprosy Relief Association), UK, 1988.

11 TALMILEP. Teaching and learning in leprosy. English Language Booklist. Published by German Leprosy Relief Association, Wurzburg, 1988.

12 World Federation for Medical Education. World Conference on Medical Education. Report. Edinburgh 7-12 August, 1988 (University of Edinburgh; Department of International Education, Teviot Place, Edinburgh EHB 9AG Scotland, UK).

13 International Foundation for Dermatology (International League of Dermatologic Societies; International Committee of Dermatology) Unpublished paper; 'Priority Mission; Establish Dermatology Centers in Developing Countries', 1988 (Chairman: New York University, Skin and Cancer Unit, 562 First Avenue, New York, NY 10016, USA).

14 Abstracts of the 13th International Leprosy Congress, The Hague, 1988. Quaderni di cooperazione sanitaria. Associazione Italiana Amici di R. Follereau, OCSI, Bologna, Italy.

15 Engers HD, Ji Baohong. Field Research in Leprosy. Scientific and technical communications, TDR (Special Programme for Research and Training in Tropical Diseases). TDR Newsletter No. 26, Summer, 1988.

16 Vaughan JP, Mills A, Smith D. The district and support for primary health care; the importance of decentralised management. Wld Hlth Forum, 1984; 5: $27-9$.

17 Vaughan JP. Editorial. J Trop Med Hyg, 1983; 86: 167-9.

18 McDougall AC, Georgiev GD. Multiple drug therapy for HD: will the light fail without new concepts and strategies? The Star, 1988; 47: 1-2 and 16.

19 WHO. Report of a meeting on methods for the rapid assessment of the leprosy situation. Geneva, 15-16 April, 1988. WHO/CDS/LEP/88.2.

20 Fox W, in Tuberculosis \& Leprosy. Brit Med Bull 1988; 44: No. 3.

${ }^{21}$ Georgiev GD, McDougall AC. The Family: a neglected but potentially valuable element in the control of leprosy. (in preparation).

22 Winsley BE, McDougall AC, Brown KE. Chemotherapy of Leprosy: 'Bubble' or 'Calendar' packs for Administration of Rifampicin, Dapsone, Clofazamine or Prothionamide/Ethionamide. Int J Le pr, 1983; 51: 592-4. Correspondence.

${ }^{23}$ Georgiev GD, Kielstrup RW. Blister calendar packs for the implementation of multiple drug therapy in DANIDA-assisted leprosy control projects in India. Lepr Rev, 1987: 58: 249-55.

${ }^{24}$ Georgiev GD, McDougall AC. Blister calendar packs: potential for improvement and utilisation of multiple drug therapy in leprosy control programmes. Int $J$ Lepr; 1988; 56, in press.

25 McDougall AC, Georgiev GD. HD; educational material for patients and their families. In preparation. 